\title{
Ecological Species, Multispecies, and Oaks
}

\author{
Leigh Van Valen
}

Taxon, Vol. 25, No. 2/3. (May, 1976), pp. 233-239.

Stable URL:

http://links.jstor.org/sici?sici=0040-0262\%28197605\%2925\%3A2\%2F3\%3C233\%3AESMAO\%3E2.0.CO\%3B2-H

Taxon is currently published by International Association for Plant Taxonomy (IAPT).

By purchasing content from the publisher through the Service you agree to abide by the Terms \& Conditions of Use, available at http://www.jstor.org/about/terms.html. These Terms \& Conditions of Use provide, in part, that this Service is intended to enable your noncommercial use of the content. For other uses, please contact the publisher of the journal. Publisher contact information may be obtained at http://www.jstor.org/journals/iapt.html.

Each copy of any part of the content transmitted through this Service must contain the same copyright notice that appears on the screen or printed page of such transmission.

For more information regarding this Service, please contact service@jstor.org. 
TAXON 25(2/3): 233-239. MAY 1976

\title{
ECOLOGICAL SPECIES, MULTISPECIES, AND OAKS
}

\author{
Leigh Van Valen*
}

\begin{abstract}
Summary
Oaks exemplify problems with the reproductive species concept which motivate a reconsideration of the use and nature of species. Ecology is important in the reconsideration. The species level is usually overemphasized in evolutionary thought; selection acts on phenotypes and any mutualistic units. Standard definitions tend to inhibit free conceptual progress. Multispecies, sets of broadly sympatric species that exchange genes, may occur among animals as well as plants and may conceivably bridge kingdoms. This phenomenon can be adaptively important. There may be taxa without species. The degree of modality of adaptive zones can be investigated empirically.
\end{abstract}

Muller (1952) and more directly Burger (1975) have shown that North American populations of oaks (Quercus) cut across the frame of reference of the now usual concept of species. This discordance may well be widespread among plants and microorganisms and seems to occur for some animals; oaks are merely conspicuous and well studied. I believe with Burger that the situation is sufficiently serious that a reconsideration of the nature of species is needed. I agree with his conclusions but go beyond them. My concern is with the nature of processes rather than terms for them, although the latter level is sometimes more convenient for discussion.

The usual concept of species can be stated as follows (Mayr, I 970): "Species are groups of interbreeding natural populations that are reproductively isolated from other such groups." This concept is grandly called "the biological species concept." But that is an arbitrary appropriation of a term with a more general and earlier meaning. I will instead use the term "reproductive species concept."

Simpson (I96I) proposed a modification of the reproductive species concept to fit it to the numerous cases where the two defining criteria are irrelevant: "An evolutionary species is a lineage (an ancestral-descendent sequence of populations) evolving separately from others and with its own unitary evolutionary role and tendencies". I will modify Simpson's concept, first stating the revised version formally and then justifying it.

My underlying framework is radical and includes the beliefs (I) that genes are of minor importance in evolution and should ordinarily be considered there in nearly the same degree (if often not for the same reasons) as other molecules, (2) that the control of evolution is largely by ecology and the constraints of individual development, and (3) that selection acts primarily on phenotypes, which are the building-blocks of communities. A species is one kind of unit of evolution, although there are many other kinds, but how best to say so precisely?

\section{The Ecological Species Concept}

The following definition is a vehicle for conceptual revision, not a standing monolith.

A species is a lineage (or a closely related set of lineages) which occupies an adaptive zone minimally different from that of any other lineage in its range and which evolves separately from all lineages outside its range.

A lineage is a clone or an ancestral-descendent sequence of populations. A

* Department of Biology, University of Chicago, Chicago, Illinois 60637 . 
population is a group of individuals in which adjacent individuals at least occasionally exchange genes with each other reproductively, and in which adjacent individuals do so more frequently than with individuals outside the population.

Lineages are closely related if they have occupied the same adaptive zone since their latest common ancestor. If their adaptive zone has changed since then, they are closely related if the new adaptations have been transferred among the lineages rather than originating separately in each.

An adaptive zone (Van Valen, I97I) is some part of the resource space together with whatever predation and parasitism occurs on the group considered. It is a part of the environment, as distinct from the way of life of a taxon that may occupy it, and exists independently of any inhabitants it may have. The word "zone," although entrenched, is perhaps unfortunate in suggesting the necessary existence of natural boundaries or subcontinuities in the resource space. The boundaries of an adaptive zone may be fixed and if so will remain the same whatever species are present, like apartments in an apartment house or a surface with basins separated by ridges. Alternatively there may be no such pre-existing boundaries, as with an Iroquois long house or a flat surface, and yet subdivision can be imposed on it by the nature of the particular species that happen to be present together. Which of these intergrading alternatives on the modality of the resource space is most prevalent is an unresolved, in fact nearly unstudied, and important empirical question.

The degree of difference in adaptive zones required will vary from case to case. Dandelions (Taraxacum officinale) have sympatric clones that differ slightly as to the part of the resource space occupied (Gadgil and Solbrig, 1972), and even if these do not in fact interbreed it is arbitrary whether they are placed in the same or different species.

"Range" is both geographical and temporal. In cases of geographic or temporal variation of the adaptive zone of a species, it may occasionally happen (I know of no real cases, but the possibility is usually ignored) that some other species in part A of the range may be more similar adaptively to the first species as it exists in part $B$ of the range than is the first species as it exists in part $\mathrm{A}$. This is a minor semantic complication which does not seem worth incorporating into the definition, although a real case would be interesting ecologically. Separate evolution is, as Simpson (196I) noted, the underlying reason for the importance of reproductive isolation. It therefore seems appropriate to use it directly. As is the case in the real world, this criterion has fuzzy boundaries.

For instance, it is arbitrary whether otherwise similar populations on isolated islands are called different species. I would not want to make such a splitting, because their evolution is still sufficiently similar and splitting would unnecessarily' complicate biogeographic theory and practical systematics, but the decision seems to be one of taste rather than biology. The populations are, after all, separate. It is for us to determine, for our own purposes, whether their evolution is controlled by pressures sufficiently different that the evolution of these populations is also separate. I believe that this criterion is the one most commonly applied to such situations in practice, at least implicitly.

It may seem that sympatric but isolated populations with similar phenotypes (sib species) present a problem, but they would not persist together if they did not occupy minimally different adaptive zones.

An operational criterion for the occupation of different adaptive zones is a difference in the ultimately regulating factor, or factors, of population density (cf. Van Valen, I973). Some species thus occupy more than one low-level adaptive zone.

Reproductive isolation of allopatric populations is of minor evolutionary importance and needs little consideration. For instance, Zouros (1974) and others have found that ecological difference is more closely related to genic difference than is the occurrence of reproductive isolation. Schwarz (1974) gives other evidence and concludes that speciation occurs by ecological change, any reproductive isolation being incidental. 
Ghiselin (1975) has made a useful advance by considering species to be "the most extensive units in the natural economy such that reproductive competition [for genes] occurs among their parts." However, such competition occurs simultaneously at many levels with different time scales. The "most extensive" might perhaps be entire trophic levels competing reproductively for free energy, and indirectly for the preservation of their genes. I therefore find this proposal incomplete.

Species are maintained for the most part ecologically, not reproductively. Completely asexual communities would perhaps be as diverse as sexual ones, with numerous subcontinuities and even discontinuities. This suggests but does not require that the main criterion of species be ecological. Heed (1963) found the phenotypic diversity for a group of Drosophila to be similar in different places, but in some places the morphs belonged to the same species and in some places to different species. A similar situation, where morphs and species are almost interchangeable in a community, may hold for the snail Cepaea (Clarke, I 962) and for spruce (Picea; Stern and Roche, I974, pp. I 32-138). Cases of character displacement and character release are evidence for a similar significance of continuous variation. It is the ultimate regulatory factors of its population density that determine whether a phenotype will persist in a community.

\section{Evolution and the Ecological Species}

It may well be that Quercus macrocarpa in Quebec exchanges many more genes with local Q. bicolor than it does with Q. macrocarpa in Texas. Considering the easily detectable proportion of intermediate individuals ("hybrids") in Quebec and the short-range gene dispersal of most plants (cf. Ehrlich and Raven, I 969; Levin and Kerster, I974), it would be surprising if this were not the case. The nature of the selection that keeps the two species largely discrete, whether based on a strong environmental subcontinuity or on developmental ("genomic") integration, is unknown. Stebbins (1970) gave evidence for the maintenance of such a situation over millions of years for another pair of species of Quercus. A set of broadly sympatric species that exchange genes in nature can be called a multispecies. (The "syngameon" of Grant [1957, I97I] is a similar concept although restricted to hybridization as a method of gene exchange. However, this term was originally defined by Lotsy [1925, I93I] as meaning any Mendelian population, as Dobzhansky [195I] noted, and Cuenot [195I] used it even more broadly for any set of potentially interfertile organisms, including specifically the entire genus Canis. Turesson's ecospecies and coenospecies are based on ability to hybridize, not on gene flow in nature [Stebbins, 1950]).

The ecological species concept treats gene flow differently depending on whether it is sympatric or allopatric. This distinction is partly arbitrary but has a reason. Q. macrocarpa and Q. bicolor are evolutionarily and ecologically largely discrete, and their broad sympatry over most of their range precludes subspecific designation. Moreover, each varies geographically. The possibility of multispecies with widely dissimilar components, discussed below, accentuates the usefulness of a distinction. At the other extreme, subspecies of the deermouse Peromyscus maniculatus are allopatric and of ten differ in major aspects of habitat use, yet they do intergrade and something coinciding with the reproductive species concept in this case seems useful. Homo sapiens has been a similar species.

Higher taxa may almost fit the definition of the ecological species concept, whence the word "minimally" with reference to the difference in adaptive zones. This delimits species from higher taxa and, as the end of a possible continuum, is why species are less arbitrary taxa than are those in higher categories. It is also why the species category itself is the least arbitrary category. However, the ecological species concept is similar to ecological interpretations of higher taxa (Simpson, 1953; Van Valen, I97I) and so helps in conceptually unifying all categories. A symposium published in the December, 1973, issue of Systematic Zoology shows an apparent consensus that evolutionary taxonomy is a simple combination of cladistics and resemblance. The addition of another dimension by 
the explicit use of adaptation, however, makes classification closer to the actual processes of evolution.

The apparent fact that species can originate from intermediate individuals (this seems to have happened in oaks: Q. alvordiana as discussed by Tucker, I 952) permits the possibility that some such species have a multiple origin, from geographically separate intermediates expanding with the expansion of an intermediate environment. The lack of reproductive isolation between the more extreme species makes interbreeding of such expanding populations likely when they meet. Conversely, one species can expand and incorporate some or even all the surviving genes of another (the compilospecies of Harlan and de Wet, I963).

Ecotypes differ from species in being multiply derived from an ancestral stock and usually in being allopatric or parapatric to it. However, a geographically continuous ecotype regionally sympatric with its ancestor would be a species. Ecotypes restricted to small, unique areas of serpentine-derived or lead-polluted soil would be marginal cases and indicate a mechanism of origin for species if the edaphic conditions were more widespread.

Most importantly, however, incomplete reproductive isolation of species permits better evolutionary adaptation. Adaptations useful to only one species can easily be kept from the other, while adaptations useful to both can get to both wherever they originate (Brues, I964, I973, I974, and unpublished). This is true for adaptations useful to both species in only part of their range as well as for adaptations of general use. It would be desirable to survey $Q$. macrocarpa and $Q$. bicolor electrophoretically in different parts of their range to see how important this phenomenon has been. And the multispecies, more extensive than the ecological species, does not have all its seeds in one ecological basket. As Burger (I975) notes, the Quercus situation is relevant to the interspecific continuity of subspecies postulated by Coon (1962) (which even Dobzhansky [1970, p. 392] has accepted, without mentioning Coon), Freudenthal (1965, I968, and personal communication), and Martin (1970), and discussed in terms of genetics by Van Valen (1966) and Brues (1 964, I 973, I 974). It is difficult to see how such an advantageous situation could be selected for directly, however, and it is probably a byproduct of other phenomena.

There may be taxa without species. Rubus, Crataegus, and the Enterobacteriaceae are possible examples, and the dandelion case is conceptually similar. The problem resulting from this possibility would be nomenclatural and not scientific. Why, other than for names, must there always be species? And even names can be treated non-traditionally. It seems preferable to see whether there are in fact objectively bounded clusters more or less comparable in adaptive scope to those in other taxa, rather than starting from an assumption of the existence of species and then trying to find their boundaries (cf. Rahn, 1929; Cowan, 1962; Hutchinson, 1968).

The modality of a broad adaptive zone can be defined as the degree to which it is partitioned when the effects of the included species on the adaptive zone itself are eliminated. In those parts of an adaptive zone which can suitably be represented by a multidimensional space, the modality is the density of clustering in this space of the images of points (or small regions) of the physical space in the part of the real world we are considering. For example, as a simple case with some applicability to herbivores, we can take the entire world with two dimensions of wetness and primary productivity. The wetness dimension will contain a strong subcontinuity in the region onto which bogs and marshes map, since they are rare in relation to waters and dry land, and there will perhaps be no marginal subcontinuity at all in the dimension of productivity although there are obvious interactions.

Statistically, I have defined (Van Valen, 1974) the modality

$$
M=\frac{\sum_{i} \sum_{j} d^{2}{ }_{i j}-\text { (uniform) }}{\frac{N^{2}}{2}-\text { (uniform) }}, \text { where } d_{i j} \text { is the }
$$


Euclidean distance between any two points, and (uniform) is the value of the summation when the same number of points are distributed uniformly in a hypersphere with diameter equal to the distance between the extreme observed points. $\mathrm{N}^{2}$ is the maximum value of the double summation and occurs when half the points 2

are at each end of the diameter. $M$ will then range from $\circ$ for no modality to I for a clustering of all points into two. It can be negative when there is unimodality.

The variables should obviously be made equivalent, as by dividing each by its mean. But there is a serious problem in the application of $M$ when measurements on different variables are best taken at physical points or different sizes of regions per unit, as with size of seeds and availability of holes for cover. There may be thousands of seeds, each representing one datum (perhaps weighted by nutritive value) to be plotted, in a region with one hole. A bird may need one hole but many seeds, so sampling one seed in the region is inadequate. $M$ can be calculated independently for each variable, but their combination is awkward although relevant to the species that inhabit the adaptive zone.

The detailed pattern of natural variation itself, within perhaps more than among populations, phenotypic perhaps more than genotypic, is of considerable interest from the viewpoint of adaptation. "Difficult," predominantly asexual, taxa may be the best groups with which to study this. Even they confound (I) biologically relevant subcontinuities in the environment, (2) effects of competition, and (3) epistatic effects of different phenotypes and genotypes on fitness (isolated phenotypic and genotypic adaptive peaks in a uniform environment). But controls are possible and the discontinuities among sexual species limit the scope of their variation in a way that is irrelevant to this problem.

Just as at least some bacteriophage exchange genes with their prey, it may be that gene exchange occurs in other cases of intimate symbiosis, e.g. mycorrhizal associations. It is even conceivable that genes are transferred between insects and plants by means of those viruses which somehow grow in both (cf. Anderson, I 970; Zhdanov and Tikchonenko, I974). A possible example has recently been described between carnivorans and primates (Todaro, Sherr, Benveniste, Lieber, and Melnick, 1974; Sherr and Todaro, I974; Benveniste and Todaro, 1974). Such situations would be marginal examples of multispecies. In an important but obscurely published paper, Durden (I969) has proposed that there are of ten geographic clines between the extremes of one and two reproductive species, the intermediates being multispecies-like.

From the point of view of ecological interactions, and therefore with respect to the operation of (and to some extent the response to) natural selection, the specieslevel unit in a community is fuzzily bounded. The possibly mutualistic nature of chloroplasts and some other organelles is repeated by definitely mutualistic interactions that are less highly integrated (Margulis, 1970). Lichens are commonly treated as species with a dual ancestry. Reef corals and many other organisms with a heterotroph ancestry are partly to wholely autotrophic (Odum, I97 I ; Zucker, I 973; Muscatine, 1973, 1974) because of endosymbiotic algae which function as chloroplasts. Should such ecological units be considered species? The only important problems are the gradation of mutualism into occasional interactions of otherwise separate individuals, and the possibility of nontransitive mutualistic associations. A double genome is accepted for lichens. Mutualistic units compete with each other and with nonmutualistic species for a community's resources and in this respect behave as (suboptimal) coalitions in $n$-person zero-sum game theory.

It is unclear why multispecies seem to occur less commonly among metazoans than elsewhere. Burger (197.5) suggests that the more complex structure (i.e. development) and more precise mating of many metazoans may be crucial. Additional possibilities are sharper delineation of adaptive zones, if this occurs, and the seemingly greater rarity of closely related sympatric species. Controls on these variables are possible and can help their evaluation. There may nevertheless be metazoan multispecies. Fischer-Piette (various papers reviewed by Van Valen, 1969) has described a possible case in the limpet Patella, and others may occur in the 
rotifer Polyartbra (Pejler, I956), the abalone Haliotis (Owen, McLean, and Meyer, 1971), the fish Etbeostoma (Echelle, Echelle, Smith, and Hill, 1975), and the mussel Mytilus (Seed, 1972). A theory which denies the possibility of multispecies inhibits their discovery.

\section{Acknowledgements}

W. Burger's analysis of oaks provided the stimulus for writing up these ideas. I thank him, N. Flesness, M. T. Ghiselin, H. W. Kerster, D. A. Levin, V. C. Maiorana, R. R. Sokal, V. Thompson, and W. Wimsatt for related discussions.

\section{References}

Anderson, N. G. 1970 - Evolutionary significance of virus infection. Nature 227: 1 346I 347 .

Benveniste, R. E., and G. J. Todaro 1974 - Evolution of C-type viral genes: inheritance of exogenously acquired viral genes. Nature 252:456-459.

Brues, A. M. 1964 - Selective factors in gene flow [abstract]. Amer. Jour. Phys. Anth. 22: 507 .

Brues, A. M. 1973 - Models applicable to geographic variation in man. In Computer Simulation in Human Population Studies (B. Dyke and J. W. MacCluer, eds.), pp. I 29-I 4I. New York: Academic Press.

BRUEs, 1974 - Models for evolution in a polytypic species [abstract]. Amer. Jour. Phys. Anth. 40: I 3I-I 32 .

BURger, W. I975 - The species-concept in Quercus. Taxon 24:45-50.

Clarke, B. 1962 - Balanced polymorphism and the diversity of sympatric species. In Taxonomy and Geography (D. Nichols, ed.), pp. 47-70. London: Systematics Association (Publ. 4).

Coon, C. S. 1962 - The Origin of Races. New York: Knopf. 724 pp.

Cowan, S. T. 1962 - The microbial species - a macromyth? Symp. Soc. Gen. Microbiol. I2: 433-455.

Cuenot, L. I95 I - L’Évolution Biologique. Paris: Masson et Cie. 592 pp.

Dobzhansky, Th. I95 I - Genetics and the Origin of Species. 3rd ed. New York: Columbia Univ. Press. $364 \mathrm{pp}$.

Dobzhansky, Th. I 970 - Genetics of the Evolutionary Process. New York: Columbia Univ. Press. 505 pp.

Durden, C. J. I 969 - Ecological aspects of the species concept. Armadillo Pap. I: I-I 4 .

Echelle, A. A., A. F. Echelle, M. H. Smith, and L. G. Hill 1975 - Analysis of genic continuity in a headwater fish, Etheostoma radiosum (Percidae). Copeia (1975): 197204.

EhrLICH, P. R., and P. H. Raven I 969 - Differentiation of populations. Science 165: I $228-1232$.

Freudenthal, M. 1965 - Betrachtungen über die Gattung Cricetodon. Koninkl. Nederlandse Akad. Wetensch. (B) 68:293-305.

Freudenthal, M. I968 - On the mammalian fauna of the Hipparion-beds in the Calatayud-Teruel Basin (Prov. Zaragoza, Spain). IV. The genus Megacricetodon (Rodentia). Koninkl. Nederlandse Akad. Wetensch. (B) 71: 57-72.

GAdGIL, M., and O. T. Solbrig 1972 - The concept of $r$ - and $K$-selection: evidence from wild flowers and some theoretical considerations. Amer. Nat. I06: I4-3I.

Ghiselin, M. T. I975 - A radical solution to the species problem. Syst. Zool. 23 (for 1974): $536-544$.

Grant, V. I 947 - The plant species in theory and practice. In The Species Problem (E. Mayr, ed.), pp. 39-80. Washington: Amer. Assoc. Adv. Sci.

Grant, V. 1971 - Plant Speciation. New York: Columbia Univ. Press. 435 pp.

Harlan, J. R., and J. M. J. DE WET I 963 - The compilospecies concept. Evolution I7: 497-501.

Heed, W. B. 1963 - Density and distribution of Drosophila polymorpha and its color alleles in South America. Evolution 17: 502-518. 
Hutchinson, G. E. 1968 - When are species necessary? In Population Biology and Evolution (R. C. Lewontin, ed.), pp. I77-186. Syracuse: Syracuse Univ. Press.

Levin, D. A., and H. W. Kerster 1974 - Gene flow in seed plants. Evol. Biol. 7: 139220.

Lotsy, J. P. I 925 - Species or Linneon? Genetica 7: 487-506.

Lotsy, J. P. I93 I - On the species of the taxonomist and its relation to evolution. Genetica I 3: I-I6.

Margulis, L. I970 - Origin of Eukaryotic Cells. New Haven: Yale Univ. Press. 350 pp.

Martin, R. A. I 970 - Line and grade in the extinct medius species group of Sigmodon. Science 167: I 504-I 506.

MaYr, E. 1970 - Populations, Species, and Evolution. Cambridge: Harvard Univ. Press. $453 \mathrm{pp}$.

MulLeR, C. H. I952 - Ecological control of hybridization in Quercus: a factor in the mechanism of evolution. Evolution 6: I47-I6I.

Muscatine, L. 1973 - Nutrition of corals. In Biology and Geology of Coral Reefs (O. A. Jones and R. Endean, eds.), vol. 2, pp. 77-I Is. New York: Academic Press.

Muscatine, L. 1974 - Endosymbiosis of cnidarians and algae. In Coelenterate Biology (L. Muscatine and H. M. Lenhoff, eds.), pp. 359-395. New York: Academic Press.

Odum, E. P. I97 I - Fundamentals of Ecology. 3rd ed. Philadelphia: Saunders. 574 pp.

Owen, B., J. H. McLean, and R. Meyer I97 I - Hybridization in the eastern Pacific abalones (Haliotis). Bull. Los Angeles Co. Mus. Nat. Hist., Sci., 9: I-37.

PeJLeR, B. I956 - Introgression in planktonic Rotatoria with some points of view on its causes and conceivable results. Evolution Io: 246-26I.

RAHN, O. 1929 - Contributions to the classification of bacteria. Zentralbl. Bakteriol. Parasitenk. Infektionskrank. (Abt. 2) 78: I-2 I.

SCHWARZ, S. S. 1974 - Intraspecific variability and species-formation: evolutional and genetical aspects of the problem. Trans. First Int. Theriological Congress 2: I $36-139$.

SEED, R. 1972 - Morphological variations in Mytilus edulis Linnaeus and M. galloprovincialis Lamarck from the coasts of France. Cahiers Biol. Mar. I 3: 357-384.

SHERR, C. J. and G. J. Todaro I 974 - Radioimmunoassay of the major group specific protein of endogenous baboon type $C$ viruses. Virology 6I: I68-I8I.

Simpson, G. G. I953 - The Major Features of Evolution. New York: Columbia Univ. Press. $434 \mathrm{pp}$.

Simpson, G. G. 196I - Principles of Animal Taxonomy. New York: Columbia Univ. Press. 247 pp.

Stebbins, G. L. 1950 - Variation and Evolution in Plants. New York: Columbia Univ. Press. 643 pp.

Stebbins, G. L. 1970 - Variation and evolution in plants. In Essays in Evolution and Genetics (M. K. Hecht and W. C. Steere, eds.), pp. 173-208. New York: AppletonCentury-Crofts.

StERN, K., and L. Roche I 974 - Genetics of Forest Ecosystems. New York: SpringerVerlag. $330 \mathrm{pp}$.

Todaro, G. J., C. J. Sherr, R. E. Benveniste, M. M. Lieber, and J. L. Melnick $1974-$ Type $C$ viruses of baboons: isolation from normal cell cultures. Cell 2: 55-6I.

Van Valen, L. 1966 - On discussing human races. Persp. Biol. Med. 9: 377-383.

Van Valen, L. 1969 - Variation genetics of extinct animals. Amer. Nat. 103: 193-224.

VAN VALEN, L. I 97 I - Adaptive zones and the orders of mammals. Evolution 25:420-428.

VAN VALEN, L. 1973 - Pattern and the balance of nature. Evol. Theory I: 3 I-49.

VAN VALEN, L. 1974 - Multivariate structural statistics in natural history. Jour. Theor. Biol. 45: 235-247; 48 : 501.

Zhdanov, V. M., and T. I. Tiкchonenko I 974 - Viruses as a factor of evolution: exchange of genetic information in the biosphere. Adv. Virus Res. 19: 361-394.

Zouros, E. 1974 - Genic differentiation associated with the early stages of speciation in the mulleri subgroup of Drosophila. Evolution 27 (for 1973): 601-62 I.

ZuCKER, W. H. 1973 - Fine structure of planktonic foraminifera and their endosymbiotic algae. Dissert. Abst. Int. (B) 34: 1003. 
http://www.jstor.org

\title{
LINKED CITATIONS
}

- Page 1 of 3 -

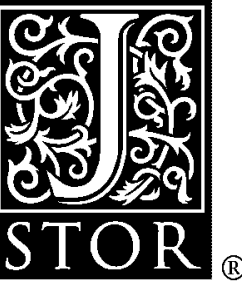

You have printed the following article:

Ecological Species, Multispecies, and Oaks

Leigh Van Valen

Taxon, Vol. 25, No. 2/3. (May, 1976), pp. 233-239.

Stable URL:

http://links.jstor.org/sici?sici=0040-0262\%28197605\%2925\%3A2\%2F3\%3C233\%3AESMAO\%3E2.0.CO\%3B2-H

This article references the following linked citations. If you are trying to access articles from an off-campus location, you may be required to first logon via your library web site to access JSTOR. Please visit your library's website or contact a librarian to learn about options for remote access to JSTOR.

\section{References}

\section{The Species Concept in Quercus}

William C. Burger

Taxon, Vol. 24, No. 1. (Feb., 1975), pp. 45-50.

Stable URL:

http://links.jstor.org/sici?sici=0040-0262\%28197502\%2924\%3A1\%3C45\%3ATSCIQ\%3E2.0.CO\%3B2-1

Analysis of Genic Continuity in a Headwater Fish, Etheostoma radiosum (Percidae)

Anthony A. Echelle; Alice F. Echelle; Michael H. Smith; Loren G. Hill

Copeia, Vol. 1975, No. 2. (May 23, 1975), pp. 197-204.

Stable URL:

http://links.jstor.org/sici?sici=0045-8511\%2819750523\%293\%3A1975\%3A2\%3C197\%3AAOGCIA\%3E2.0.CO\%3B2-6

\section{Differentiation of Populations}

Paul R. Ehrlich; Peter H. Raven

Science, New Series, Vol. 165, No. 3899. (Sep. 19, 1969), pp. 1228-1232.

Stable URL:

http://links.jstor.org/sici?sici=0036-8075\%2819690919\%293\%3A165\%3A3899\%3C1228\%3ADOP\%3E2.0.CO\%3B2-Q

\author{
The Concept of r- and K-Selection: Evidence from Wild Flowers and Some Theoretical \\ Considerations \\ Madhav Gadgil; Otto T. Solbrig \\ The American Naturalist, Vol. 106, No. 947. (Jan. - Feb., 1972), pp. 14-31. \\ Stable URL: \\ http://links.jstor.org/sici?sici=0003-0147\%28197201\%2F02\%29106\%3A947\%3C14\%3ATCORAK\%3E2.0.CO\%3B2-5
}


http://www.jstor.org

\title{
LINKED CITATIONS
}

- Page 2 of 3 -

\author{
A Radical Solution to the Species Problem \\ Michael T. Ghiselin \\ Systematic Zoology, Vol. 23, No. 4. (Dec., 1974), pp. 536-544. \\ Stable URL: \\ http://links.jstor.org/sici?sici=0039-7989\%28197412\%2923\%3A4\%3C536\%3AARSTTS\%3E2.0.CO\%3B2-B
}

\section{The Compilospecies Concept}

Jack R. Harlan; J. M. J. de Wet

Evolution, Vol. 17, No. 4. (Dec., 1963), pp. 497-501.

Stable URL:

http://links.jstor.org/sici?sici=0014-3820\%28196312\%2917\%3A4\%3C497\%3ATCC\%3E2.0.CO\%3B2-\%23

Density and Distribution of Drosophila polymorpha and Its Color Alleles in South America William B. Heed

Evolution, Vol. 17, No. 4. (Dec., 1963), pp. 502-518.

Stable URL:

http://links.jstor.org/sici?sici=0014-3820\%28196312\%2917\%3A4\%3C502\%3ADADODP\%3E2.0.CO\%3B2-2

\section{Line and Grade in the Extinct Medius Species Group of Sigmodon}

Robert A. Martin

Science, New Series, Vol. 167, No. 3924. (Mar. 13, 1970), pp. 1504-1506.

Stable URL:

http://links.jstor.org/sici?sici=0036-8075\%2819700313\%293\%3A167\%3A3924\%3C1504\%3ALAGITE\%3E2.0.CO\%3B2-1

Ecological Control of Hybridization in Quercus: A Factor in the Mechanism of Evolution Cornelius H. Muller

Evolution, Vol. 6, No. 2. (Jun., 1952), pp. 147-161.

Stable URL:

http://links.jstor.org/sici?sici=0014-3820\%28195206\%296\%3A2\%3C147\%3AECOHIQ\%3E2.0.CO\%3B2-7

Introgression in Planktonic Rotatoria with Some Points of View on Its Causes and Conceivable Results

Birger Pejler

Evolution, Vol. 10, No. 3. (Sep., 1956), pp. 246-261.

Stable URL:

http://links.jstor.org/sici?sici=0014-3820\%28195609\%2910\%3A3\%3C246\%3AIIPRWS\%3E2.0.CO\%3B2-2 
http://www.jstor.org

\section{LINKED CITATIONS \\ - Page 3 of 3 -}

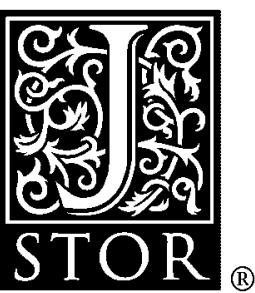

\section{Variation Genetics of Extinct Animals}

Leigh Van Valen

The American Naturalist, Vol. 103, No. 931. (May - Jun., 1969), pp. 193-224.

Stable URL:

http://links.jstor.org/sici?sici=0003-0147\%28196905\%2F06\%29103\%3A931\%3C193\%3AVGOEA\%3E2.0.CO\%3B2-C

\section{Adaptive Zones and the Orders of Mammals}

Leigh Van Valen

Evolution, Vol. 25, No. 2. (Jun., 1971), pp. 420-428.

Stable URL:

http://links.jstor.org/sici?sici=0014-3820\%28197106\%2925\%3A2\%3C420\%3AAZATOO\%3E2.0.CO\%3B2-D

Genic Differentiation Associated with the Early Stages of Speciation in the mulleri Subgroup of Drosophila

E. Zouros

Evolution, Vol. 27, No. 4. (Dec., 1973), pp. 601-621.

Stable URL:

http://links.jstor.org/sici?sici=0014-3820\%28197312\%2927\%3A4\%3C601\%3AGDAWTE\%3E2.0.CO\%3B2-J 